\title{
Genetic Evaluation of Stillbirth in United States Holsteins Using a Sire-Maternal Grandsire Threshold Model
}

\author{
J. B. Cole, ${ }^{1}$ G. R. Wiggans, and P. M. VanRaden \\ Animal Improvement Programs Laboratory, Agricultural Research Service, USDA, Beltsville, MD 20705-2350
}

\begin{abstract}
A sire-maternal grandsire threshold model was used for genetic evaluation of stillbirth in US Holsteins. Calving ease and stillbirth records for herds reporting at least 10 dead calves were extracted from the Animal Improvement Programs Laboratory database. About half of the 14 million calving ease records in the database had a known livability score, mostly from herds processed by Dairy Records Management Systems (Raleigh, NC). Calf livability scores of 2 and 3, representing calves born dead and calves that died within $48 \mathrm{~h}$ of parturition, respectively, were combined into a single category. The model included effects of herd-year, year-season, parity-sex, sire, birth year group of sire, maternal grandsire (MGS), and birth year group of MGS. Herd-year, sire, and MGS were random effects. Mean predicted transmitting abilities, expressed as the expected percentage of stillbirths, were 7.9 and 8.6 for direct and maternal stillbirths, respectively. Mean reliabilities for both the direct and maternal effects were $45 \%$. Correlations among domestic and Interbull stillbirth solutions on the underlying scale for bulls with at least $90 \%$ reliability ranged from 0.63 to 0.90 across countries for direct stillbirths and from 0.69 to 0.96 for maternal stillbirths, indicating that results were generally consistent with those from other countries. There was no evidence of a genetic trend for either trait. More complete recording of stillbirth scores would improve reliabilities and could allow for evaluations of other breeds.
\end{abstract}

Key words: sire-maternal grandsire model, stillbirth, threshold model

\section{INTRODUCTION}

Stillborn calves, those born dead or dying within $48 \mathrm{~h}$ of birth, are of increasing concern to US dairy producers. Meyer et al. (2001a) found that the still-

Received July 7, 2006.

Accepted November 1, 2006.

${ }^{1}$ Corresponding author: jcole@aipl.arsusda.gov birth (SB) rate increased from $9.5 \%$ in 1985 to $13.2 \%$ in 1996 , costing producers $\$ 125.3$ million per year. Genetic evaluations for calving ease (CE) have been computed in the United States since 1977 (Berger, 1994; Van Tassell et al., 2003), but evaluations are not provided for other traits related to calving, such as SB. Philipsson (1996) reported that about half of all stillborn calves are born without difficulty, emphasizing the desirability of separate evaluations for dystocia and SB.

Trait definitions vary slightly between countries, with most defining SB as those calves born dead or dying within $24 \mathrm{~h}$ of parturition (Philipsson et al., 1979), although Germany, Israel, and the United States include deaths within $48 \mathrm{~h}$ of birth (Weller et al., 1988; Berger et al., 1998; Interbull, 2004b). Patterson et al. (1987) found that $57.4 \%$ of preweaning losses in beef cattle under range conditions occur within $24 \mathrm{~h}$ postpartum, and $65.7 \%$ of all calf losses occur within $48 \mathrm{~h}$ of parturition. Thus, the 48 -h definition has the advantage of including more perinatal losses than the 24-h definition. Breed differences play a role in perinatal mortality (Philipsson, 1976; Thompson et al., 1981), and Rossoni et al. (2005) reported that $10 \%$ of Italian Brown Swiss calves did not suckle by the third meal offered postpartum, contributing to increased postnatal mortality. Trait definitions, incidence rates, and heritabilities used by the United States and several other countries are presented in Table 1. Incidence rates and heritabilities were similar when comparing parities across countries despite differences in trait definition, with the exception of Sweden.

Berger et al. (1998) found that data were insufficient to justify the development of a routine national evaluation for SB at that time, but Meyer et al. (2001b) later demonstrated the feasibility of a linear model evaluation for SB using US data. About 3.5 million SB records were added to the national database between December 1998 and February 2006, suggesting that sufficient data for development of a national evaluation are now available (Figure 1). The purpose of this study was to determine the feasibility of implementing a routine genetic evaluation for SB in US Holsteins. 
Table 1. Properties of genetic evaluations of stillbirth in Holstein populations

\begin{tabular}{|c|c|c|c|c|c|c|c|}
\hline \multirow[b]{2}{*}{ Country } & \multirow[b]{2}{*}{ Parity } & \multirow[b]{2}{*}{ Definition $^{1}$} & \multirow{2}{*}{$\begin{array}{c}\text { Incidence } \\
\%\end{array}$} & \multirow[b]{2}{*}{ Model $^{2}$} & \multicolumn{2}{|c|}{ Heritability } & \multirow[b]{2}{*}{ Reference } \\
\hline & & & & & Sire & Maternal & \\
\hline Canada $^{3}$ & All & 24 & 8.3 & ST MGS LM & 0.03 & 0.06 & Luo et al. (1999) \\
\hline Denmark & 1 & 24 & 9.2 & MT MGS TM & 0.03 & 0.04 & Hansen et al. (2004) \\
\hline Finland & $1-3$ & 24 & - & MT MGS LM & 0.02 & 0.01 & Interbull (2004a) \\
\hline Germany & All & 48 & 6.8 & MT AM LM & 0.05 & 0.05 & Interbull (2004b) \\
\hline Holland & $\begin{array}{l}1 \\
2+\end{array}$ & 24 & $\begin{array}{r}11.0 \\
5.0\end{array}$ & ST MGS LM & $\begin{array}{l}0.03 \\
0.01\end{array}$ & $\begin{array}{l}0.05 \\
0.01\end{array}$ & Interbull (2005b) \\
\hline Israel & 1 & 48 & 7.4 & ST MGS LM & 0.01 & 0.01 & Interbull (2005a) \\
\hline Sweden & $\begin{array}{l}1 \\
2\end{array}$ & 24 & $\begin{array}{l}7.1 \\
2.7\end{array}$ & ST MGS TM & $\begin{array}{l}0.12 \\
0.04\end{array}$ & $\begin{array}{l}0.08 \\
0.02\end{array}$ & Steinbock et al. (2003) \\
\hline Switzerland & All & 24 & - & MT AM LM & 0.03 & 0.03 & Interbull (2005c) \\
\hline United States $^{3}$ & $\begin{array}{l}1 \\
2+\end{array}$ & 48 & $\begin{array}{r}11.0 \\
5.6\end{array}$ & ST MGS LM & $\begin{array}{l}0.01 \\
0.04\end{array}$ & $\begin{array}{l}0.02 \\
0.03\end{array}$ & Meyer et al. (2001b) \\
\hline United States & All & 48 & 6.9 & ST MGS TM & 0.03 & 0.06 & Cole et al. (2006) \\
\hline
\end{tabular}

${ }^{1} 24=$ stillbirths recorded as born dead or died within $24 \mathrm{~h}$ of birth, $48=$ stillbirths recorded as born dead or died within $48 \mathrm{~h}$ of birth.

${ }^{2}$ MT AM LM = multiple-trait linear animal model; MT MGS LM = multiple-trait sire-maternal grandsire linear model; ST MGS LM = single-trait sire-maternal grandsire linear model; ST MGS TM = single-trait sire-maternal grandsire threshold model. When both linear and threshold model analyses were provided in an analysis, only the threshold model results are presented.

${ }^{3}$ Evaluations were for research purposes only.

\section{MATERIALS AND METHODS}

\section{Data}

Data originated both from DHIA and from AI organizations through collection by their cooperating progeny test herds. Almost all data were originally collected through AI organizations, but over time, the portion of data collected through DHIA has increased so that nearly all recent data were collected via DHIA and processed through dairy record processing centers, principally Dairy Records Management Systems (Raleigh, NC).

Calving ease and SB records for Holstein calvings were extracted from the Animal Improvement Programs Laboratory database and subjected to a series of data quality edits (Van Tassell et al., 2003). Herds

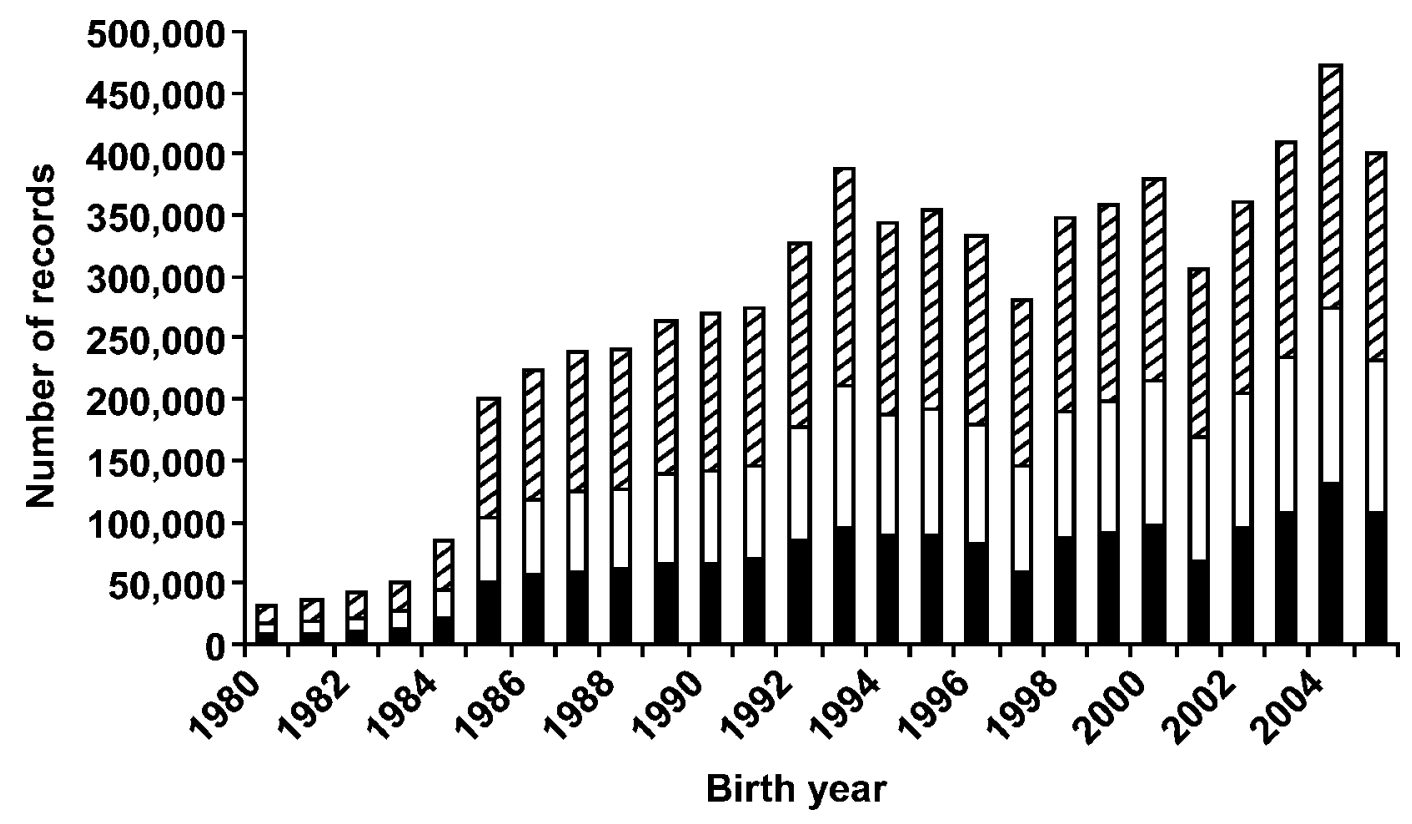

Figure 1. Number of Holstein stillbirth records in the national calving ease database with usable calf livability scores for cows in first (solid bars), second (open bars), and third and later (hatched bars) parities. 
Table 2. Number of records and stillbirth rates in US dairy breeds ${ }^{1}$

\begin{tabular}{lrcc}
\hline Breed & Records & $\begin{array}{c}\text { Live } \\
\text { births, } \\
\%\end{array}$ & $\begin{array}{c}\text { Stillbirths, } \\
\%\end{array}$ \\
\hline Ayrshire & 1,800 & 94.5 & 5.5 \\
Brown Swiss & 16,910 & 94.1 & 5.9 \\
Guernsey & 1,971 & 92.2 & 7.8 \\
Holstein & $7,301,976$ & 93.1 & 6.7 \\
Jersey & 36,918 & 94.9 & 5.1 \\
Milking Shorthorn & 346 & 95.7 & 4.3 \\
\hline
\end{tabular}

${ }^{1}$ Statistics were calculated from the national database and included all records with valid calf livability scores; no edits were applied to these data.

were required to have at least 10 calvings resulting in dead calves in the database to be included in the SB evaluation. This was done to avoid bias from herds that reported only live calves. Only data from single births were used. Calf livability is reported on a 3point scale, with 1,2 , and 3 representing calves born alive, calves born dead, and calves that died within 48 $\mathrm{h}$ of parturition, respectively. A score of 0 indicates that no livability score was reported for that calving; missing observations were not included in the analysis. For evaluation, scores of 2 and 3 were combined into a single category representing stillborn calves. Only Holstein records were used because available data were insufficient to permit the evaluation of other breeds (Table 2). The SB data are a subset of the CE data; however, the entire CE pedigree file was used for the SB evaluation. Including sires and maternal grandsires (MGS) without observations produced pedigree indices instead of PTA for 2,597 bulls. The distribution of $\mathrm{SB}$ and $\mathrm{CE}$ scores in the raw and edited data sets are presented in Table 3; the edited data set included about 6 million records. A total of 135,235 bulls were represented, 44,290 of which were AI bulls from participating AI organizations.

\section{Genetic Evaluation Model}

The sire-MGS (S-MGS) model implemented for the routine $\mathrm{CE}$ genetic evaluation (Van Tassell et al., 2003) was used to analyze the SB data:

$$
\mathrm{y}=\mathrm{HY}+\mathrm{YS}+\mathrm{PS}+\mathrm{Y}_{\mathrm{s}}+\mathrm{Y}_{\mathrm{m}}+\mathrm{s}+\mathrm{m}+\mathrm{e}
$$

where $\mathrm{y}$ is the SB score, HY is the random herd-year effect, YS is the fixed year-season effect, PS is the fixed parity-sex effect, $Y_{S}$ is the fixed sire birth year effect, $\mathrm{Y}_{\mathrm{m}}$ is the fixed MGS birth year effect, $\mathrm{s}$ is the random sire effect, $\mathrm{m}$ is the random MGS effect, and e is the random residual effect. Parities were first, second, and third and later. Year-season groups began in October and May.

The Bayesian analysis (co)variance components of Cole et al. (2007) were used: herd-year, 0.087; sire, 0.009; S-MGS, 0.018; and residual, 1.000. These components correspond to sire and S-MGS heritabilities of 0.030 and 0.065 , respectively. The estimated genetic correlation of direct and maternal components was 0.002. The estimated correlation of sire and MGS components was 0.331 , which includes the portion of the direct effect of the MGS also included in the S-MGS effect.

Sire and MGS solutions on the underlying scale were transformed and expressed as the expected percentage of SB (\%SB). Genetic bases for sire solutions, called service sire SB (SSB), and MGS solutions, called daughter SB (DSB), were defined by groups of bulls born between 1996 and 2000 and between 1991 and 1995, respectively. Five-year averages were used to set the base because of high year-to-year volatility attributable to large effects of some sires of sons in some individual years. A base of $8 \%$ was used for both SSB and DSB.

Predicted transmitting abilities for \%SB were computed similarly to those for the percentage of difficult

Table 3. Distribution of livability and calving ease scores before and after editing in the data set used for the national genetic evaluation

\begin{tabular}{|c|c|c|c|c|c|c|c|c|c|}
\hline \multirow[b]{3}{*}{ Calving ease score } & \multicolumn{5}{|c|}{ Before editing } & \multicolumn{4}{|c|}{ After editing } \\
\hline & \multicolumn{4}{|c|}{ Livability score $^{1}$} & \multirow[b]{2}{*}{ Total } & \multicolumn{3}{|c|}{ Livability score $^{2}$} & \multirow[b]{2}{*}{ Total } \\
\hline & 0 & 1 & 2 & 3 & & 1 & 2 & 3 & \\
\hline $1=$ No problem & $4,807,707$ & $5,325,523$ & 189,529 & 23,274 & $10,346,033$ & $4,560,249$ & 175,140 & 20,424 & $4,755,803$ \\
\hline $2=$ Slight problem & 908,760 & 609,923 & 59,951 & 2,956 & $1,581,590$ & 522,073 & 56,090 & 2,534 & 580,697 \\
\hline $3=$ Needed assistance & 772,338 & 455,919 & 83,351 & 3,832 & $1,315,440$ & 393,940 & 78,559 & 3,347 & 475,846 \\
\hline $4=$ Considerable force & 221,797 & 128,366 & 45,251 & 2,024 & 397,438 & 111,373 & 42,130 & 1,742 & 155,245 \\
\hline
\end{tabular}

${ }^{1}$ Livability scores: $0=$ no score reported, $1=$ calf born alive, $2=$ calf born dead, $3=$ calf born alive but died within $48 \mathrm{~h}$ of birth. Scores of 2 and 3 were combined for evaluation.

${ }^{2}$ Records with livability scores of 0 were not included in the national evaluation. 
Table 4. Distribution of livability scores by parity and sex of calf before editing in the data set used for the national genetic evaluation

\begin{tabular}{|c|c|c|c|c|c|c|c|c|c|c|c|c|c|}
\hline \multirow[b]{3}{*}{ Score $^{1}$} & \multicolumn{4}{|c|}{ First parity } & \multicolumn{4}{|c|}{ Second parity } & \multicolumn{4}{|c|}{ Third parity } & \multirow[b]{3}{*}{ Total } \\
\hline & \multicolumn{2}{|c|}{ Male $^{2}$} & \multicolumn{2}{|c|}{ Female } & \multicolumn{2}{|c|}{ Male } & \multicolumn{2}{|c|}{ Female } & \multicolumn{2}{|c|}{ Male } & \multicolumn{2}{|c|}{ Female } & \\
\hline & $\mathrm{n}$ & $\%$ & $\mathrm{n}$ & $\%$ & $\mathrm{n}$ & $\%$ & $\mathrm{n}$ & $\%$ & $\mathrm{n}$ & $\%$ & $\mathrm{n}$ & $\%$ & \\
\hline 0 & 926,717 & 51.1 & 944,452 & 51.6 & $1,057,675$ & 49.6 & 980,352 & 49.7 & $1,523,371$ & 47.7 & $1,397,066$ & 47.9 & $6,829,633$ \\
\hline 1 & 776,724 & 42.9 & 803,991 & 43.9 & $1,017,466$ & 47.7 & 947,436 & 48.1 & $1,580,216$ & 49.5 & $1,443,377$ & 49.6 & $6,569,210$ \\
\hline 2 & 104,261 & 5.7 & 78,042 & 4.2 & 52,669 & 2.5 & 38,270 & 1.9 & 80,749 & 2.5 & 63,722 & 2.2 & 417,713 \\
\hline 3 & 4,636 & 0.3 & 5,445 & 0.3 & 3,580 & 0.2 & 5,105 & 0.3 & 6,110 & 0.3 & 8,752 & 0.3 & 33,628 \\
\hline
\end{tabular}

${ }^{1}$ Livability scores are: $0=$ no score reported, $1=$ calf born alive, $2=$ calf born dead, $3=$ calf born alive but died within $48 \mathrm{~h}$ of birth. Scores of 2 and 3 were combined for evaluation.

${ }^{2}$ Percentages sum to $100 \%$ within parity-sex groups.

births in heifers presented in Van Tassell et al. (2003) as

$$
\begin{gathered}
1-\% S B^{*}=\overline{F\left(T_{1}-\varepsilon^{*}+c\right)} \\
\% S B=1-F\left[-\varepsilon+F^{-1}\left(1-\% S B^{*}\right)+\overline{\varepsilon^{*}}\right]
\end{gathered}
$$

where $\mathrm{F}$ is the standard normal cumulative density function, $\mathrm{F}^{-1}$ is the inverse of the standard normal cumulative density function, $\mathrm{T}_{1}$ is the threshold between SB scores of 1 and 2 on the observed scale, $\varepsilon$ is the solution on the underlying scale with fixed MGS birth-year solutions added to the MGS solution, and * denotes the group of animals used to define the base. A constant, $c$, is used to achieve the desired base, and $\mathrm{c}$ in equation [2] is replaced with $\varepsilon$ in equation [3]; $\varepsilon$ consists of the random MGS solution plus the fixed MGS birth-year group solution.

\section{RESULTS AND DISCUSSION}

The distribution of livability scores by parity and sex of calf for the raw and edited data sets are presented in Tables 4 and 5 . A total of $57 \%$ of SB calves in first and second parities were bulls, which decreased to $55 \%$ in third parity. These results are consistent with those of Meyer et al. (2001b), who also found that male calves were more likely to be stillborn. Half of the CE records in the national database had missing calf livability scores. An additional 7\% were excluded because they were from herds that reported fewer than 10 dead calves. The final data set contained 6 million records, a substantial increase from the 3.4 million records available to Berger et al. (1998).

The phenotypic trend for SB is shown in Figure 2. Stillbirths averaged 10.5 and $5.9 \%$ in heifers and cows, respectively, from 1980 to 2005 . The incidence of SB increased from $11.2 \%$ in 1980 to $12.0 \%$ in 2004 for heifers, and decreased from $5.8 \%$ in 1980 to $5.6 \%$ in 2005 for multiparous cows. The apparent decrease in heifer SB from $12.0 \%$ in 2004 to $11.1 \%$ in 2005 may indicate that not all records from 2005 had been forwarded to the Animal Improvement Programs Laboratory. Year-to-year variation was more pronounced in heifers than in cows. The occurrence of SB to heifers in the current study was slightly lower than that reported by Meyer et al. (2001a), 10.1 vs. $11.1 \%$ from 1985 to 1996. Stillbirths in the current data set increased from 8.6 to $10.6 \%$ in heifers and from 4.8 to $5.9 \%$ in cows from 1985 to 1996 . The change in heifer SB was much smaller than that reported by Meyer et al. (2001a), 2 vs. $3.7 \%$ over the same time period. Those

\begin{tabular}{|c|c|c|c|c|c|c|c|c|c|c|c|c|c|}
\hline \multirow[b]{2}{*}{ Score $^{1}$} & \multicolumn{4}{|c|}{ First parity } & \multicolumn{4}{|c|}{ Second parity } & \multicolumn{4}{|c|}{ Third parity } & \multirow[b]{2}{*}{ Total } \\
\hline & $\mathrm{n}$ & $\%$ & $\mathrm{n}$ & $\%$ & $\mathrm{n}$ & $\%$ & $\mathrm{n}$ & $\%$ & $\mathrm{n}$ & $\%$ & $\mathrm{n}$ & $\%$ & \\
\hline 1 & 698,580 & 87.1 & 715,651 & 90.1 & 871,692 & 94.4 & 808,698 & 95.4 & $1,325,081$ & 94.4 & $1,208,250$ & 94.9 & $5,627,952$ \\
\hline 2 & 99,423 & 12.4 & 74,002 & 9.3 & 48,737 & 5.3 & 34,572 & 4.1 & 73,913 & 5.3 & 56,959 & 4.5 & 387,606 \\
\hline 3 & 4,139 & 0.5 & 4,898 & 0.6 & 3,130 & 0.3 & 4,425 & 0.5 & 5,174 & 0.3 & 7,556 & 0.6 & $2,931,922$ \\
\hline Total & 802,142 & & 794,551 & & 923,559 & & 847,695 & & $1,404,168$ & & $1,272,765$ & & $6,044,880$ \\
\hline
\end{tabular}

Table 5. Distribution of livability scores by parity and sex of calf in the edited data set used for the national genetic evaluation

${ }^{1}$ Stillbirth scores: 1 = calf born alive, 2 = calf born dead, $3=$ calf born alive but died within $48 \mathrm{~h}$ of birth. Scores of 2 and 3 were combined for evaluation.

${ }^{2}$ Percentages sum to $100 \%$ within parity-sex groups. 


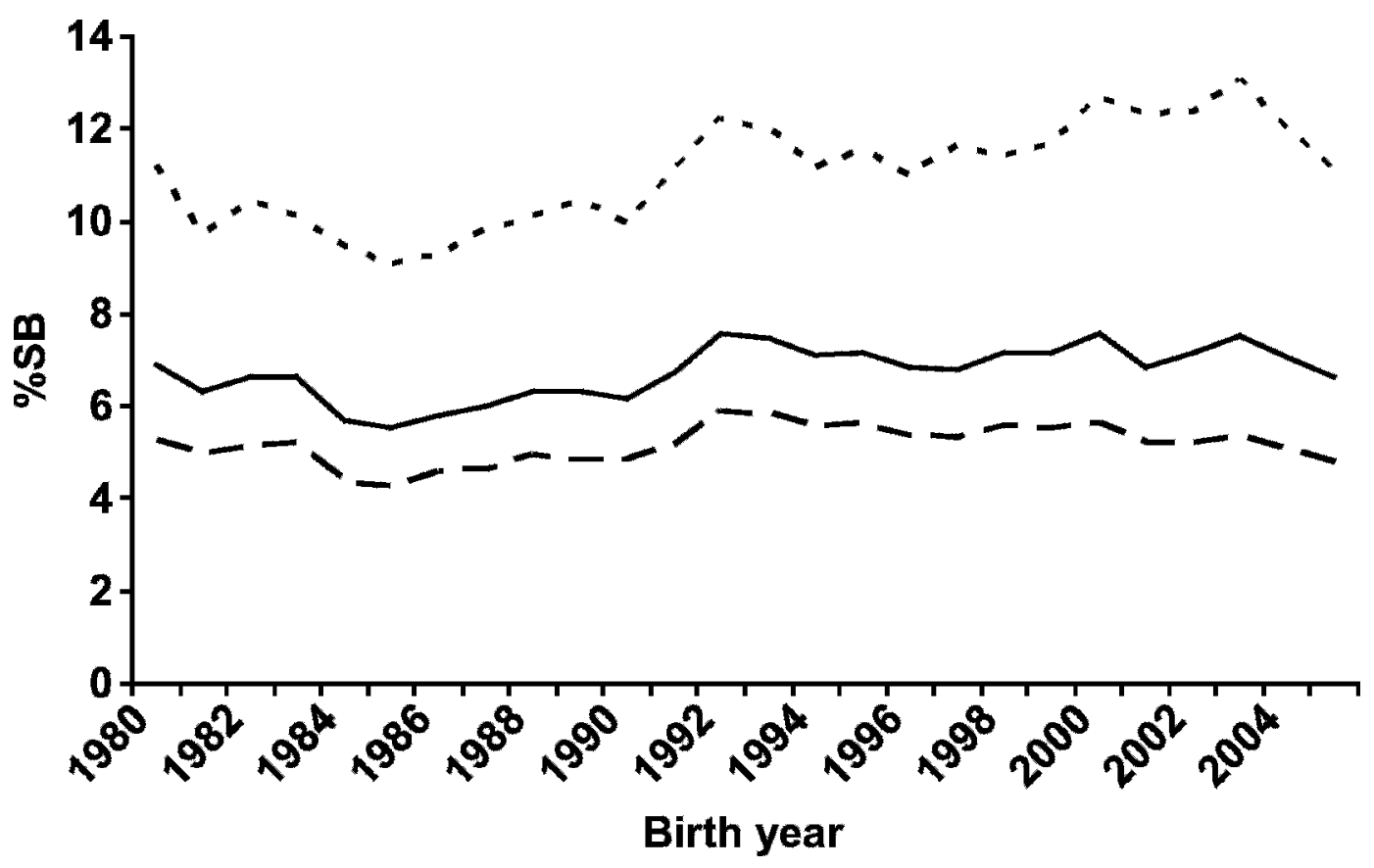

Figure 2. Phenotypic trend for stillbirths (\%SB) in primiparous heifers (dotted line), cows (broken line), and all animals (solid line).

differences may be due in part to the requirement by Meyer et al. (2001a) that $>90 \%$ of all calf deaths be reported in order for a herd to be included in their study, whereas reporting of $\geq 10$ dead calves was required for inclusion in the current study.

Neither phenotypic nor genetic trends were significant. It is likely that the rate of increase in SB has decreased as a result of assortative mating of bulls with low PTA for CE to heifers. Correlated responses to selection for improved $\mathrm{CE}$ are also possible; Cole et al. (2007) estimated genetic correlations between direct $\mathrm{CE}$ and SB and MGS CE and SB of 0.67 and 0.63 , respectively.

Statistical properties of solutions to the S-MGS model are presented in Table 6. Characteristics of the solutions were similar to results from the routine Holstein CE evaluation (Van Tassell et al., 2003). The range and $\mathrm{SD}$ of the herd-year solution was smaller

Table 6. Number of levels of effects, ranges, and SD of solutions from sire-maternal grandsire threshold model equations

\begin{tabular}{lrcc}
\hline Effect & Levels & Range & SD \\
\hline Herd-year & 73,683 & 3.47 & 0.20 \\
Year-season & 53 & 0.31 & 0.08 \\
Parity-gender & 6 & 0.60 & 0.25 \\
Sire birth year & 19 & 0.07 & 0.02 \\
Maternal grandsire birth year & 37 & 0.25 & 0.05 \\
Sire & 135,235 & 0.50 & 0.03 \\
Maternal grandsire & 135,235 & 0.90 & 0.05 \\
\hline
\end{tabular}

for SB than for $\mathrm{CE}$, and was much larger than for any other effect. This lower variation reflects the fact that many more herd-years were included in the $\mathrm{CE}$ data than in the SB data, resulting in fewer SB herds with extreme solutions resulting from the extreme category problem (Harville and Mee, 1984; Misztal et al., 1989). The parity-sex effect was much smaller for SB than $\mathrm{CE}, 0.60$ vs. 1.02 , which is consistent with phenotypic trends showing that the difference between first and later parities is smaller for SB than for CE. Sire and MGS birth-year group effects were small and consistent with the lack of genetic trend for SB shown in Figure 3, which is in agreement with the report by Meyer et al. (2001b) of an unfavorable but nonsignificant trend in SSB and DSB. The increase in mean PTA for DSB in 2002 is attributable to a prominent sire of sons with extremely poor merit for DSB. Sire and MGS solutions were smaller than those for CE, and the MGS range was larger, reflecting the larger MGS variance.

When included in the model as a fixed effect, CE scores had a larger effect on SB than year-season, sire, or MGS effects (Cole et al., 2006). The magnitude of the parity-sex effect also decreased by about half, which is attributable to the increased risk of dystocia, and corresponding increased risk of SB, in heifers vs. cows. Calvings reported as requiring considerable force or being extremely difficult were more likely (1.7 and 2.3 times, respectively) to result in a stillborn calf than calvings scored as no problem. Rank correlations of 




Figure 3. Mean service sire (solid line) and daughter (broken line) PTA for the percentage of stillbirths (\%SB) by birth year of the bull.

solutions on the underlying scale from models with and without the effect of $\mathrm{CE}$ were 0.81 and 0.95 for SSB and DSB, respectively (Cole et al., 2006). Although those results indicated substantial reranking of bulls, only $3 \%$ of sires had changes of greater than 2 standard deviations on the underlying scale for SSB; only $1 \%$ of bulls had changes greater than 1 standard deviation for DSB. These findings are consistent with those of Meyer et al. (2001b), who argued for the inclusion of CE scores in models of SB to account for average differences in SB associated with different levels of dystocia.

The comparison of service sire and daughter \%SB is shown in Figure 4. Mean PTA were 7.9 and $8.6 \%$ for SSB and DSB, respectively. The distribution of SSB was more compact than that of DSB, which was expected because the genetic variance of SSB is smaller than that of DSB. The correlation between SSB and DSB on both the observed and underlying scales was 0.20 for all sires $(\mathrm{n}=44,290)$, and 0.29 for sires with reliabilities of $90 \%$ or more $(\mathrm{n}=951)$, slightly smaller than the genetic correlation of 0.33 used in the evaluation.

Denmark, Finland, Israel, the Netherlands, and Sweden currently participate in the Interbull SB evaluation. Correlations among US SB solutions on the underlying scale with Interbull evaluations on foreign scales for bulls with at least $90 \%$ reliability in both countries ranged from 0.63 to 0.90 for direct SB and 0.69 to 0.96 for maternal SB, indicating that results from this analysis were generally consistent with those in other countries. These ranges were similar to the range of correlations among Interbull participants. Correlations were not uniformly high because of differences in model and trait definitions among countries.

Distributions of the reliability of service sire and daughter \%SB for both traits in both data sets are heavily right-skewed and reflect lower progeny numbers than are desirable from the perspective of genetic evaluation (Figure 5). This is likely because a few bulls had a large number of records available, which gave high reliabilities, but most bulls had a very small number of daughters and received correspondingly low reliabilities. In addition, Van Tassell et al. (2003) reported a consistent upward bias attributable to a simplifying assumption used in the computation of the reliabilities, that all relatives and contemporaries are perfectly evaluated, although most sires still had lower reliabilities (46 to 50\%). This was more pronounced for SB than CE; most bulls had reliabilities of less than $45 \%$, and the mode was in the 36 to $40 \%$ category. The implementation of a routine national genetic evaluation for SB is expected to show the value of reporting SB data and lead to an increase in the number of usable records collected by the National Association of Animal Breeders through the progeny test herds of 


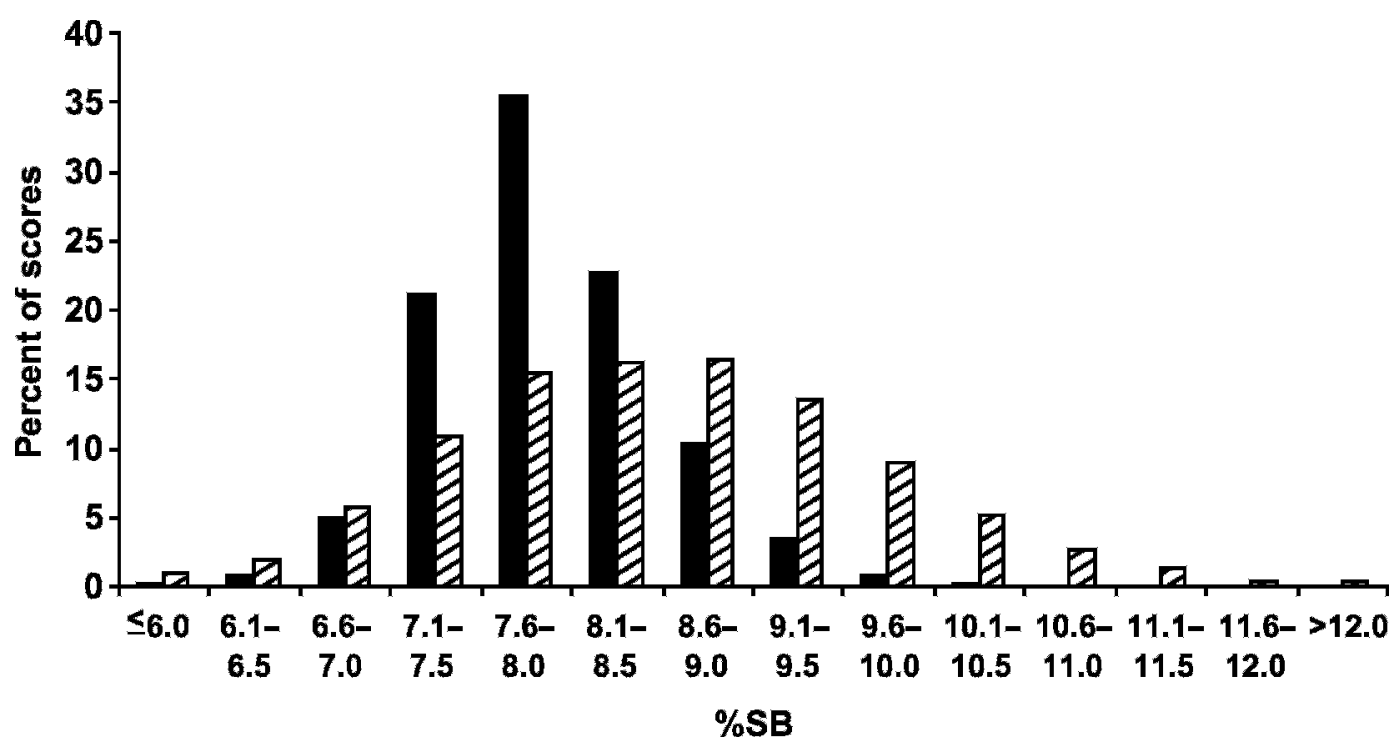

Figure 4. Distribution of all service sire (solid bars) and daughter (hatched bars) PTA for the percentage of stillbirths (\%SB).

AI organizations, as well as by participants in National DHIA and other milk recording agencies. An increase in records should result in higher reliabilities for bulls.

Although Meyer et al. (2001b) made a compelling argument for including dystocia in models for SB, the model adopted for routine evaluation in the United States does not include the fixed effect of CE. There are 2 reasons for this: ease of interpretation and trait harmonization with participants in the Interbull SB evaluation. Predicted transmitting abilities computed from a model that includes dystocia must be interpreted as the expected percentage of SB after the effect of dystocia has been removed, which presents a formidable educational challenge. Given the small magnitude of most changes in sire and MGS solutions on the underlying scale when moving from a model including

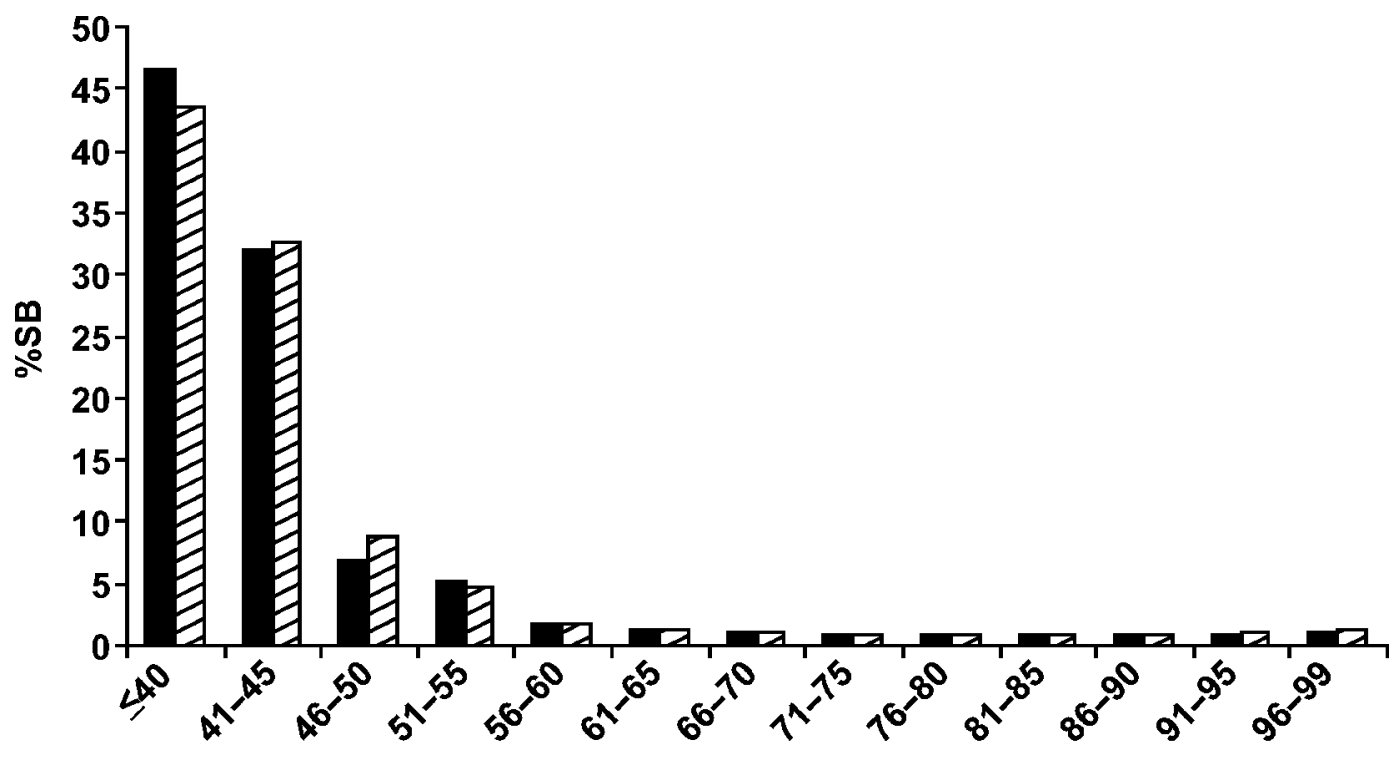

Reliability, \%

Figure 5. Distributions of reliabilities (\%) for service sire (solid bars) and daughter (hatched bars) PTA for the percentage of stillbirths (\%SB). 
dystocia to one without, and given that reliabilities do not differ between the 2 , the more parsimonious model is preferred. None of the participants in the March 2006 Interbull test evaluation for Holstein SB (Denmark, Finland, the Netherlands, Israel, and the United States) included dystocia in their SB evaluation.

Denmark (Interbull, 2003) and the Netherlands (Interbull, 2005b) use multiple-trait models that include SB in first and later parities as correlated traits, and Wiggans et al. (2006) demonstrated the feasibility of modeling parities as separate traits using a threshold model for CE in the United States. Steinbock et al. (2003) reported genetic correlations between first and later parities in Swedish Holsteins of 0.45 for SSB and 0.48 for DSB. Harbers et al. (2000) reported correlations between first and later parities of 0.52 and 0.78 for SSB and DSB, respectively, in Dutch Holsteins. Modeling first and later parities as correlated traits or including CE and SB in a multiple-trait evaluation may be more beneficial than accounting for dystocia in the current model.

\section{CONCLUSIONS}

Approximately half of the records in the national $\mathrm{CE}$ data set were not usable in the SB evaluation because they had missing calf livability scores. This resulted in much lower reliabilities (averaging 45\%) for SB than for CE. There was no evidence of consistent phenotypic or genetic trends for SB from 1980 to 2005. An industry-wide effort is needed to improve recording for calf livability, although accuracy could be improved in the short run by development and implementation of a multiple-trait evaluation including CE and SB.

A routine evaluation for SB in US Holsteins was developed and implemented in August 2006. Direct and maternal SB were included in Lifetime Net Merit for Holsteins starting in August 2006. Domestic data from February 2006 were provided to Interbull for inclusion in the March 2006 international pilot run for $\mathrm{CE}$ and $\mathrm{SB}$, and the United States expects to participate in routine Interbull evaluations beginning in November 2006 .

\section{ACKNOWLEDGMENTS}

The authors are grateful to Jeff Berger and Kent Weigel for their valuable suggestions and discussion. Two anonymous reviewers also provided helpful feedback. John Clay and the staff of Dairy Records Management Systems (Raleigh, NC) provided invaluable assistance with the SB data. Ignacy Misztal and Shogo Tsuruta of the University of Georgia provided the CBLUP90IOD and RENUMF90 computer programs.

\section{REFERENCES}

Berger, P. J. 1994. Genetic prediction for calving ease in the United States: Data, models, and use by the dairy industry. J. Dairy Sci. 77:1146-1153.

Berger, P. J., J. R. Thompson, and C. G. Sattler. 1998. Preliminary investigations on the feasibility of a stillbirth evaluation for the USA. Interbull Bull. 18:28-30.

Cole, J. B., G. R. Wiggans, and P. M. VanRaden. 2006. Genetic evaluation of stillbirth in United States Holsteins using a sirematernal grandsire threshold model. Commun. 01-28 in Proc. 8th World Congr. Genet. Appl. Livest. Prod., Belo Horizonte, Brazil.

Cole, J. B., G. R. Wiggans, P. M. VanRaden, and R. H. Miller. 2007. Stillbirth (co)variance components for a sire-maternal grandsire threshold model and development of a calving ability index for sire selection. J. Dairy Sci. 90:2489-2496.

Hansen, M., I. Misztal, M. S. Lund, J. Pedersen, and L. G. Christensen. 2004. Undesired phenotypic and genetic trend for stillbirth in Danish Holsteins. J. Dairy Sci. 87:1477-1486.

Harbers, A., L. Segeren, and G. de Jong. 2000. Genetic parameters for stillbirth in the Netherlands. Interbull Bull. 25:117-122.

Harville, D. A., and R. W. Mee. 1984. A mixed-model procedure for analyzing ordered categorical data. Biometrics 40:393-408.

Interbull. 2005a. Description of National Genetic Evaluation System (Israel). http://www-interbull.slu.se/national_ges_info2/forms/ isr/form_ca_isr_hol_050610.pdf Accessed June 6, 2006.

Interbull. 2005b. Description of National Genetic Evaluation System (the Netherlands). http://www-interbull.slu.se/national_ges_ info2/forms/nld/form_ca_nld_all_050201.pdf Accessed May 25, 2006.

Interbull. 2005c. Description of National Genetic Evaluation System (Switzerland). http://www-interbull.slu.se/national_ges_info2/ forms/che/form_ca_che_hol_091105.pdf Accessed May 25, 2006.

Interbull. 2004a. Description of National Genetic Evaluation System (Finland). http://www-interbull.slu.se/national_ges_info2/ forms/fin/form_ca_fin_ays_041004.pdf Accessed May 25, 2006.

Interbull. 2004b. Description of National Genetic Evaluation System (Germany). http://www-interbull.slu.se/national_ges_info2/ forms/deu/form_ca_deu_hol_jer_ays_041004.pdf Accessed May $25,2006$.

Interbull. 2003. Description of National Genetic Evaluation System (Denmark). http://www-interbull.slu.se/national_ges_info2/ forms/dnk/form_ca_dnk_all_030115.pdf Accessed June 6, 2006.

Luo, M. F., P. J. Boettcher, J. C. M. Dekkers, and L. R. Schaeffer. 1999. Bayesian analysis for estimation of genetic parameters of calving ease and stillbirth for Canadian Holsteins. J. Dairy Sci. 82:1848-1858.

Meyer, C. L., P. J. Berger, K. J. Koehler, J. R. Thompson, and C. G. Sattler. 2001a. Phenotypic trends in incidence of stillbirth for Holsteins in the United States. J. Dairy Sci. 84:515-523.

Meyer, C. L., P. J. Berger, J. R. Thompson, and C. G. Sattler. $2001 \mathrm{~b}$. Genetic evaluation of Holstein sires and maternal grandsires in the United States for perinatal survival. J. Dairy Sci. 84:1246-1254.

Misztal, I., D. Gianola, and J. L. Foulley. 1989. Computing aspects of a nonlinear method of sire evaluation for categorical data. J. Dairy Sci. 72:1557-1568.

Patterson, D. J., R. A. Bellows, P. J. Burfening, and J. B. Carr. 1987. Occurrence of neonatal and postnatal mortality in range beef cattle. I. Calf loss incidence from birth to weaning, backward and breech presentations, and effects of calf loss on subsequent pregnancy rate of dams. Theriogenology 28:557-569.

Philipsson, J. 1996. Strategies to reduce problems in calving performance and stillbirths by selection and differential use of bulls. Interbull Bull. 12:65-71.

Philipsson, J. 1976. Studies on calving difficulty, stillbirth, and associated factors in Swedish cattle breeds. I. General introduction and breed averages. Acta Agric. Scand. 26:151-164.

Philipsson, J., J. L. Foulley, J. Lederer, T. Liboriussen, and A. Osinga. 1979. Sire evaluation standards and breeding strategies 
for limiting dystocia and stillbirth. Report of an EEC/EAAP Working Group. Livest. Prod. Sci. 6:111-127.

Rossoni, A., C. Nicoletti, S. Ghiroldi, E. Santus, and A. Bagnato. 2005. Calf's suckling ability in Italian Brown Swiss. Interbull Bull. 33:218-221.

Steinbock, L., A. Näsholm, B. Berglund, K. Johansson, and J. Philipsson. 2003. Genetic effects on stillbirth and calving difficulty in Swedish Holsteins at first and second calving. J. Dairy Sci. 86:2228-2235.

Thompson, J. R., A. E. Freeman, P. J. Berger, and M. L. Martinez. 1981. A survey of dystocia and calf mortality in five dairy breeds. J. Dairy Sci. 64(Suppl. 1):81. (Abstr.)
Van Tassell, C. P., G. R. Wiggans, and I. Misztal. 2003. Implementation of a sire-maternal grandsire model for evaluation of calving ease in the United States. J. Dairy Sci. 86:3366-3373.

Weller, J. I., I. Misztal, and D. Gianola. 1988. Genetic analysis of dystocia and calf mortality in Israeli-Holsteins by threshold and linear models. J. Dairy Sci. 71:2491-2501.

Wiggans, G. R., C. P. Van Tassell, J. B. Cole, and L. L. M. Thornton. 2006. Genetic correlations between first and later parity calving ease in a sire-maternal grandsire model. Commun. 01-92 in Proc. 8th World Congr. Genet. Appl. Livest. Prod., Belo Horizonte, Brazil. 